\title{
LA PROTECCIÓN DEL AMBIENTE EN LA CONSTITUCIÓN DE LA REPÚBLICA
}

\section{ENVIRONMENTAL PROTECTION IN THE URUGUAYAN CONSTITUTION PROTEÇAO DO MEIO AMBIENTE NA CONSTITUIÇAO DA REPÚBLICA}

Gonzalo F. Iglesias Rossini

RESUMEN. El presente estudio aborda la protección constitucional del ambiente, la cual se encuentra no sólo recogida por el artículo 47 de la Constitución, sino también por los artículos 7, 72, y 332. El artículo 47 de la Constitución declara de interés general la protección del ambiente, lo que habilita a limitar ciertos derechos fundamentales, como la propiedad. En este sentido, en base a dicho artículo, y de la Ley $\mathrm{N}^{\circ} 17.234$, de 22 de febrero de 2000, se autoriza al Poder Ejecutivo, a propuesta del Ministerio de Ambiente, a establecer ciertas limitaciones o prohibiciones respecto a las actividades que se realicen en las áreas comprendidas en el Sistema Nacional de Áreas Naturales Protegidas y zonas adyacentes. Recientemente la Suprema Corte de Justicia analizó la constitucionalidad de esta ley en base al artículo 47 de la Constitución, la cual analizaremos también en el presente artículo.

PALABRAS CLAVE. Derecho Ambiental. Constitución Nacional. Sistema Nacional de Áreas Naturales Protegidas.

ABSTRACT. This study addresses the constitutional protection of the environment, which is granted not only by Section 47 of the Constitution, but also by Sections 7, 72, and 332. Section 47 of the Constitution declared that environmental protections is of general interest, which means that certain fundamental rights may be limited, such as the property. Based on this Section, and Law Number 17,234, dated February 22, 2000, the Executive Branch, on the motion of the Ministry of Environment, may impose certain limitations and prohibitions regarding the activities that are carried out in protected areas incorporated into the National System of Natural Protected Areas and their adjacent areas. Recently the Supreme Court has analyzed the constitutionality of this law in accordance

\footnotetext{
* Doctor en Derecho y Ciencias Sociales. Escribano Público. Asesor en Derecho Ambiental. Integrante del Centro de Derecho Ambiental de la Facultad de Derecho. Universidad de la República. LL.M. Environmental and Energy Law. Georgetown University Law Center. Especialista en Derecho Ambiental. Universidad de Buenos Aires. Correo electrónico: gfi2@georgetown.edu
} 
with Section 47 of the Constitution, which will be addressed in this article.

KEYWORDS: Environmental Law. National Constitution. National System of Natural Protected Areas.

RESUMO. Este estudo trata da proteção constitucional do meio ambiente, incluída não apenas no artigo 47 da Constituição, mas também nos artigos 7, 72 e 332. O artigo 47 da Constituição declara de interesse geral a proteção do meio ambiente, que permite limitar certos direitos fundamentais, como a propriedade. Nesse sentido, com base no referido artigo e na Lei $n^{\circ} 17.234$, de 22 de fevereiro de 2000, autoriza-se ao Poder Executivo, por proposta do Ministério do Meio Ambiente, a estabelecer certas limitações ou proibições em relação às atividades realizadas nas áreas incluídas no Sistema Nacional de Áreas Naturais Protegidas e áreas adjacentes. Recentemente, o Supremo Tribunal de Justiça analisou a constitucionalidade desta lei com base no artigo 47 da Constituição, que também analisaremos neste artigo.

PALAVRAS-CHAVE. Direito Ambiental. Constituição Nacional. Sistema Nacional de Áreas Naturais Protegidas.

\section{Introducción}

Nuestro país protege expresamente el ambiente desde la Constitución de 1997, aunque anteriormente la doctrina consideraba que el derecho a vivir en un ambiente sano se encontraba implícitamente protegido a través de los artículos 7, 72 y 332 de la Constitución. El artículo 47 de la Constitución recibió diversas críticas por parte de la doctrina, muchas de las cuales fueron recogidas y corregidas por la Ley General de Protección del Ambiente (Ley $\mathrm{N}^{\circ} 17.283$, de 28 de noviembre de 2000).

La Constitución de la República de 1967 no contaba con disposiciones sobre la protección del ambiente; mucho menos las anteriores, de 1830 a 1967 (Magariños de Mello, 1997, p. 46). Tengamos en cuenta que en dicha época no existía una conciencia ambiental en nuestro país que motivara dicha protección constitucional. El mundo recién comenzaba a poner el tema ambiental en el tapete recién en la década del 70.

Es importante recordar que la regulación de la temática ambiental por el Derecho, tanto nacional como internacional, comienza a surgir recién con la Primera Conferencia Mundial de las Naciones Unidas Sobre el Medio Ambiente Humano, celebrada en Estocolmo (Suecia), en el año 1972. Al punto que la Declaración de Estocolmo es considerada como la piedra fundamental del Derecho Ambiental (Magariños de Mello, 1997, p. 43).

Con anterioridad existían solo algunas Constituciones europeas que preveían disposiciones que protegían el ambiente (Correa Freitas, 1997, p. 25). Lo cierto es que con poste- 
rioridad a este mojón, las Constituciones en el mundo empezaron a constitucionalizar la protección del ambiente. Similar a lo que se produjo con los Derechos Humanos, luego de la adopción en 1948 de la Declaración Universal de Derechos Humanos (Gros Espiell, 1997, p. 54). En los últimos cuarenta años, más de 100 países han adoptado el derecho a vivir en un ambiente sano en sus Constituciones .

Siguiendo la tendencia mundial, el artículo 47 de la Constitución dio paso al desarrollo del Derecho Ambiental en nuestro país, permitiendo la limitación de ciertos derechos, tales como la propiedad. Un claro ejemplo es la creación del Sistema Nacional de Áreas Naturales Protegidas (el "SNAP") a partir de la Ley N 17.234, de 22 de febrero de 2000, ya que de conformidad con el artículo $8^{\circ}$ de dicha ley, el Poder Ejecutivo, a propuesta del Ministerio de Vivienda, Ordenamiento Territorial y Medio Ambiente, puede establecer ciertas limitaciones o prohibiciones respecto a las actividades que se realicen en las áreas comprendidas en el SNAP y zonas adyacentes.

Una de las pocas sentencias ambientales que han llegado a la Suprema Corte de Justicia discutió justamente la disposición constitucional y la constitucionalidad del Sistema Nacional de Áreas Naturales Protegidas. Analizaremos dicha sentencia en el presente estudio.

En el Capítulo II del presente estudio analizaremos la protección del ambiente en la Constitución de la República. En el Capítulo III analizaremos el inciso primero del artículo 47 de la Constitución. En el Capítulo IV analizaremos el inciso segundo del artículo 47 de la Constitución. En el Capítulo V analizaremos la protección del ambiente a través de los artículos 7, 72, y 332 de la Constitución. En el Capítulo VI analizaremos la Sentencia de la Suprema Corte de Justicia, que declara la constitucionalidad de la Ley $\mathrm{N}^{\circ} 17.234$, modificada por la Ley $\mathrm{N}^{\circ}$ 17.930. Finalmente, en el Capítulo VII desarrollaremos las conclusiones del presente estudio.

II. La protección del ambiente en la Constitución de la República

La protección del ambiente aparece consagrada en el artículo 47 de la Constitución de la República, el cual se ubica dentro del Capítulo II, dentro de la Sección II (Derechos, Deberes y Garantías). Asimismo, dicha protección se desprende de los artículos 7, 72 y 332 de la Constitución de la República.

Hasta la reforma constitucional de 1997, nuestra Constitución carecía de una referencia expresa a la protección del ambiente. Sin perjuicio de ello, la doctrina reconocía su rango constitucional, ya sea por la vía del artículo 72 de la Constitución, o como extensión de otros derechos, como la vida, o la seguridad (Risso, 2006, p. 771). Pero además, cabe aclarar que previo a la reforma constitucional de 1997, nuestro país contaba con normas de rango legislativo y reglamentario, que igualmente protegían el ambiente (Gorosito, 
2019, p. 243).

A los efectos prácticos podemos diferenciar los dos incisos del artículo 47 de la Constitución de la República. El primer inciso del artículo 47, cuya redacción fue dada por la Reforma Constitucional, aprobada por plebiscito de fecha 8 de diciembre de 1996. El inciso segundo fue agregado por la Reforma Constitucional, aprobada por plebiscito de fecha 31 de octubre de 2004 .

III. La protección del ambiente en el inciso primero del artículo 47 de la Constitución de la República

El inciso primero del artículo 47 de la Constitución de la República reconoce la calidad de bien jurídico al ambiente (Biasco, 1999, p. 80). Dicho artículo, luego de la reforma constitucional de 1997, dispone que: "La protección del medio ambiente es de interés general. Las personas deberán abstenerse de cualquier acto que cause depredación, destrucción o contaminación graves al medio ambiente. La ley reglamentará esta disposición y podrá prever sanciones para los transgresores.".

Anteriormente, el artículo 47 de la Constitución de la República disponía lo siguiente: "El Estado combatirá por medio de la ley y de las Convenciones Internacionales, los vicios sociales.". Dicha disposición luego de la reforma constitucional de 1997, pasó a ser el inciso segundo del artículo 46 de la Constitución (Gros Espiell, 1997, p. 60).

El artículo 47 de la Constitución de la República, utiliza la terminología popular de la época, haciendo mención al "medio ambiente", y no al "ambiente" (Biasco, 1999, 78). Terminología tan discutida, ya que existe una preferencia a nivel doctrinario por utilizar "ambiente", en lugar de "medio ambiente". Nuestra Constitución se apartó de la Constitución de otros países, como por ejemplo la Argentina que utiliza "ambiente", y no "medio ambiente" (artículo 41).

El inciso primero del artículo 47 de la Constitución de la República se puede separar en tres secciones: una declaración de interés general, el establecimiento de un deber de abstención, y por último, un mandato reglamentario (Magariños de Mello, 1997, p. 49; Cousillas, 2011, p. 111).

La disposición constitucional establece un "sistema de garantías" con respecto a la protección del ambiente, el cual está dado por: (i) la declaración de interés general; (ii) generar la obligación de abstenerse de perjudicarlo; y (iii) prever el establecimiento de sanciones para los transgresores (Biasco, 1999, p. 80).

A. Sobre el interés general en la protección del ambiente

En primer lugar, el artículo 47 de la Constitución Nacional declara que la protección del ambiente es de interés general. Este tipo de declaración es novedosa en nuestra Constitu- 
ción, ya que es utilizada para calificar la necesaria protección del ambiente; apartándose del resto de los artículos que utiliza este concepto (Gros Espiell, 1997, p. 61).

El resto de los artículos de la Constitución en que se menciona el "interés general", se realiza como criterio para que la ley (ley formal), puede usar para regular los derechos de los habitantes de la República, enumerados en los artículos 7, 32, y 36 de la Constitución (Gros Espiell, 1997, p. 61).

En primer lugar, la expresión "interés general” es utilizada en el artículo 7 de la Constitución, el cual dispone que: "Los habitantes de la República tienen derecho a ser protegidos en el goce de su vida, honor, libertad, seguridad, trabajo y propiedad. Nadie puede ser privado de estos derechos sino conforme a las leyes que se establecieren por razones de interés general." (El subrayado nos pertenece). En este artículo, la expresión "interés general" se utiliza como criterio por el cual las "leyes" pueden llegar a privar de la protección de los derechos enumerados en dicho artículo.

En segundo lugar, el artículo 32 de la Constitución dispone que: "La propiedad es un derecho inviolable, pero sujeto a lo que dispongan las leyes que se establecieren por razones de interés general. Nadie podrá ser privado de su derecho de propiedad sino en los casos de necesidad o utilidad públicas establecidos por una ley y recibiendo siempre del Tesoro Nacional una justa y previa compensación. Cuando se declare la expropiación por causa de necesidad o utilidad públicas, se indemnizará a los propietarios por los daños y perjuicios que sufrieren en razón de la duración del procedimiento expropiatorio, se consume o no la expropiación; incluso los que deriven de las variaciones en el valor de la moneda." (El subrayado nos pertenece). En este sentido, el artículo 32 de la Constitución emplea dicha expresión como criterio por el cual "las leyes" pueden reglamentar el derecho a la propiedad (Gros Espiell, 1997, p. 61).

Por último, el artículo 36 de la Constitución dispone que: "Toda persona puede dedicarse al trabajo, cultivo, industria, comercio, profesión o cualquier otra actividad lícita, salvo las limitaciones de interés general que establezcan las leyes.”. En este caso, la expresión "interés general" es utilizada para determinar eventuales limitaciones a la libertad de trabajo, de industria, de comercio, profesional o cualquier otra actividad lícita (Gros Espiell, 1997, p. 61).

Cierto sector de la doctrina entiende que la inclusión del "interés general" constituye una doble significación. En primer lugar, desde el punto de vista político, el constituyente priorizó la protección del ambiente, como una cuestión que atañe a toda la comunidad. En segundo lugar, desde el punto de vista técnico o jurídico, ya que la declaración de interés general habilita a limitar el derecho a ser protegidos en el goce de ciertos derechos fundamentales (Cousillas, 2011, p. 112). En efecto, tal como hemos adelantado, el artículo 7 de la Constitución de la República establece que: "Los habitantes de la República tienen derecho a ser protegidos en el goce de su vida, honor, libertad, seguridad, trabajo 
y propiedad. Nadie puede ser privado de estos derechos sino conforme a las leyes que se establecieren por razones de interés general." (El subrayado nos pertenece).

El interés general es definido por el Poder Legislativo, por medio de la ley, y controlado por la Suprema Corte de Justicia a través del recurso de inconstitucionalidad de las leyes, para determinar si ese interés es legítimo, o es contrario a la Constitución. Pero en este caso, la Constitución dejó en claro que la protección del ambiente es de interés general (Correa Freitas, 1997, p. 40).

El artículo $1^{\circ}$ de la Ley $\mathrm{N}^{\circ} 17.283$, declaró de interés general, de conformidad con lo establecido en el artículo 47 de la Constitución de la República:

A) La protección del ambiente, de la calidad del aire, del agua, del suelo y del paisaje.

B) La conservación de la diversidad biológica y de la configuración y estructura de la costa.

C) La reducción y el adecuado manejo de las sustancias tóxicas o peligrosas y de los desechos cualquiera sea su tipo.

D) La prevención, eliminación, mitigación y la compensación de los impactos ambientales negativos.

E) La protección de los recursos ambientales compartidos y de los ubicados fuera de las zonas sometidas a jurisdicciones nacionales.

F) La cooperación ambiental regional e internacional y la participación en la solución de los problemas ambientales globales.

G) La formulación, instrumentación y aplicación de la política nacional ambiental y de desarrollo sostenible.

Asimismo, se aclara que la declaración antes aludida es sin perjuicio de lo establecido por las normas específicas vigentes en cada una de las materias señaladas.

De todos modos, debemos concluir que esta enunciación no debe ser taxativa, ya que todas las normas de protección del ambiente son de interés general. Esto por cuanto las leyes referidas a la protección del ambiente son de interés general, independientemente de que así haya sido categorizado por el legislador, o incluso la judicatura (Cousillas, 2011, p. 113).

B. Sobre el deber de abstención de causar actos que causen degradación, destrucción o contaminación graves al medio ambiente

En segundo lugar, se establece por parte del inciso primero del artículo 47 de la Constitución, un deber de abstención por parte de todas las personas a causar cualquier acto que provoque depredación, destrucción o contaminación "graves" al medio ambiente. Esta disposición repite casi textualmente el artículo $3^{\circ}$ de la Ley $\mathrm{N}^{\circ} 16.466$, de 19 de enero de 1994, aunque acotada al impacto ambiental: "Es deber fundamental de toda persona, 
física o jurídica, abstenerse de todo acto que cause impacto ambiental que se traduzca en depredación, destrucción o contaminación graves del medio ambiente." (El subrayado nos pertenece).

En cambio, el artículo 47 de la Constitución de la República hace referencia a "todo acto" sin hacer por supuesto mención al impacto ambiental ("cualquier acto que cause depredación, destrucción o contaminación graves al medio ambiente").

Asimismo, esta disposición es repetida casi textualmente por el primer inciso del artículo $3^{\circ}$ de la Ley $\mathrm{N}^{\circ} 17.283$, aunque aclarando que las personas pueden ser tanto físicas como jurídicas, públicas y privadas: "Las personas físicas y jurídicas, públicas y privadas, tienen el deber de abstenerse de cualquier acto que cause depredación, destrucción o contaminación graves del medio ambiente.".

El Derecho a veces opta por fórmulas negativas, y otras veces por fórmulas positivas, invocando un derecho humano, es decir, el derecho a vivir en un ambiente sano y equilibrado (Durán Martínez, 1999, p. 81). En este caso, el artículo 47 de la Constitución utiliza únicamente la fórmula negativa (deber de abstención), sin hacer mención al derecho a vivir en un ambiente sano y equilibrado. Se prohíbe mediante la imposición de un deber de abstención (Gros Espiell, 1997, p. 63). Por lo tanto, la Constitución consagra un deber negativo, es decir, un deber de abstención (Correa Freitas, 1997, p. 41).

Respecto al término "personas", se ha discutido si el deber en cuestión alcanza a las personas jurídicas, o si queda limitado a las personas físicas. La doctrina mayoritariamente ha entendido que dado que la norma no distingue, el intérprete no debería distinguir, por lo que comprende a ambas personas (Gros Espiell, 1997, p. 63). Tal como hemos adelantado, esto fue solucionado por el artículo 3 de la Ley $\mathrm{N}^{\circ} 17.283$.

Es importante tener presente que este deber de abstención no implica un deber de proteger el ambiente. Aunque son dos caras de una misma moneda, es claro que la Constitución priorizó la obligación de abstención, y no realizó una referencia expresa a la obligación de proteger el ambiente, como sí sucede en otros países (como por ejemplo la Constitución de la Nación Argentina).

Posteriormente, nuestro país ha adoptado legalmente esta obligación en el inciso final del artículo 7 de la Ley $\mathrm{N}^{\circ}$ 18.308, de 18 de junio de 2008 (Ley de Ordenamiento Territorial y Desarrollo Sostenible). En efecto, dicha inciso dispone que: “(...) las personas tienen el deber de proteger el medio ambiente, los recursos naturales y el patrimonio cultural y de conservar y usar cuidadosamente los espacios y bienes, públicos territoriales." (El subrayado nos pertenece).

Por lo tanto, existe únicamente rango constitucional en la obligación de abstención o no hacer, prevista en el artículo 47 de la Constitución, y únicamente rango legal en la obligación o deber de hacer, prevista en el artículo 7 de la Ley $\mathrm{N}^{\circ} 18.308$.

Esta abstención aparece referida a tres acciones y un calificativo. Las tres acciones que 
toda persona debe abstenerse de causar son: (i) depredar; (ii) destruir, o (iii) contaminar. Pero no toda depredación, destrucción o contaminación quedan alcanzados por el deber de abstención. El texto constitucional aclara que dichos actos deben ser "graves".

Este calificativo de "grave" no es novedoso en la Constitución de la República, ya que varias disposiciones refieren al mismo. Por ejemplo, los artículos 25 ("culpa grave"), 93 (“delitos graves"), 104 (“delitos graves"), 130 ("según la importancia o gravedad del asunto"); y numeral 17 del artículo 168 (“casos graves").

Por lo tanto, se podría afirmar que la Constitución de la República sólo prohíbe (deber de abstención) los actos que causen depredación, destrucción o contaminación "graves". A contrario sensu, se podría concluir que existen actos "leves" que no quedarían comprendidos por el deber de abstención (Cousillas, 2011, p. 115). En otras palabras, el constituyente diferenció una contaminación "leve" (admitida), y una "grave" (prohibida) (Rotondo, 2015, p. 87).

Esta disposición ha sido reglamentada por el inciso segundo de la Ley $\mathrm{N}^{\circ} 17.283$, el cual dispone que: "Declárase por vía interpretativa que, a efectos de lo establecido en el artículo 47 de la Constitución de la República y en la presente disposición, se consideran actos que causan depredación, destrucción o contaminación graves del medio ambiente, aquellos que contravengan lo establecido en la presente ley y en las demás normas regulatorias de las materias referidas en el artículo $1^{\circ}$. Asimismo, se entiende por daño ambiental toda pérdida, disminución o detrimento significativo que se infiera al medio ambiente.". Por lo tanto, la solución que encontró el legislador es asimilar "grave" con ilícito (Cousillas, 2011, p. 116).

C. Sobre el mandato al legislador a reglamentar el artículo 47 de la Constitución

En tercer lugar, el artículo 47 de la Constitución mandata al legislador a reglamentar esta disposición, y aclara que podrá prever sanciones para los transgresores ("La ley reglamentará esta disposición y podrá prever sanciones para los transgresores").

Según la doctrina, se deja librado a la ley que dicte el Poder Legislativo la reglamentación de esta disposición, y al legislador el prever las sanciones para los transgresores (Correa Freitas, 1997, p. 41).

Claramente, tal como ha sido señalado por la doctrina, no era necesario aclarar que la ley podrá prever sanciones para los transgresores, en virtud de lo previsto por el párrafo 3 del artículo 85 de la Constitución, y sólo tiene sentido desde el punto de vista político, al señalar la importancia de la cuestión (Gros Espiell, 1997, p. 63).

Las conductas que son contrarias a este deber de abstención, son conductas ilícitas, tanto del punto de vista civil, administrativo, y penal (Gros Espiell, 1997, p. 63). Pero fundamentalmente, el Derecho Ambiental prioriza la recomposición. Esto se desprende 
del inciso primero del artículo 4 de la Ley $\mathrm{N}^{\circ}$ 16.466: "Sin perjuicio de las sanciones administrativas y penales que señale la ley, quien provoque depredación, destrucción o contaminación del medio ambiente en violación de lo establecido por los artículos de la presente ley, será civilmente responsable de todos los perjuicios que ocasione, debiendo hacerse cargo, además, si materialmente ello fuere posible, de las acciones conducentes a su recomposición." (El subrayado nos pertenece).

El mandato constitucional ha sido cumplido a través de la Ley $\mathrm{N}^{\circ}$ 17.283. La misma aclara en el artículo $5^{\circ}$ de manera innecesaria que: "El objetivo de la presente ley general de protección del ambiente es, en cumplimiento del mandato previsto en el artículo 47 de la Constitución de la República, establecer previsiones generales básicas atinentes a la política nacional ambiental y a la gestión ambiental coordinada con los distintos sectores públicos y privados.".

Tal como hemos adelantado, esta disposición ha sido reglamentada a través del inciso segundo del artículo $3^{\circ}$ de la Ley $\mathrm{N}^{\circ} 17.283$, declarando por vía interpretativa que, a efectos de lo establecido en el artículo 47 de la Constitución de la República, se consideran actos que causan depredación, destrucción o contaminación graves del medio ambiente, aquellos que contravengan lo establecido en dicha ley y en las demás normas regulatorias de las materias referidas en el artículo $1^{\circ}$.

De no haberse reglamentado esta disposición, habría quedado librada a la interpretación del intérprete (por ejemplo el juez competente), respecto a la gravedad de dichos actos.

D. Críticas al artículo 47 de la Constitución de la República

El artículo 47 de la Constitución de la República ha recibido diversas críticas por parte de la doctrina, algunas de las cuales han sido solucionadas por la Ley $\mathrm{N}^{\circ} 17.283$, pero otras tantas persisten.

La mayor crítica que se le puede hacer al artículo 47 de la Constitución de la República es que no se consagra expresamente un derecho a los habitantes (de las generaciones presentes y futuras) al goce y disfrute de un ambiente sano y equilibrado (Risso, 2006, p. 772; Biasco, 1999, 79).

Si bien podría quedar implícito en el artículo 72 de la Constitución, creemos que la importancia del tema hubiera ameritado que el constituyente lo hubiera plasmado a texto expreso. El constituyente descartó además la tendencia que existía en el Derecho Constitucional Comparado, sobre cómo ha encarado el tema ambiental, descartando el reconocimiento expreso (derecho) de los individuos a vivir en un ambiente sano (Gros Espiell, 1997, 60).

En este sentido, nuestro país se aparta de la tendencia que existe en otros países, en dejar plasmado expresamente dicho derecho con rango constitucional. Por ejemplo, el artículo 41 de la Constitución de la Nación Argentina establece que: "Todos los habitantes gozan 
del derecho a un ambiente sano, equilibrado, apto para el desarrollo humano y para que las actividades productivas satisfagan las necesidades presentes sin comprometer las de las generaciones futuras; y tienen el deber de preservarlo.".

Este insólito olvido por parte del constituyente - a decir de Risso Ferrand - fue corregido parcialmente por el artículo 2 de la Ley $\mathrm{N}^{\circ}$ 17.283, que consagra el derecho de los habitantes de la República a ser protegidos en el goce de un ambiente sano y equilibrado (derecho humano de tercera generación). (Risso, 2006, p. 772). De todos modos, es clara la diferencia, ya que este artículo tiene únicamente rango legal, y no constitucional. Cierto sector de la doctrina entiende que de todos modos dicho derecho aparece recogido implícitamente en la Constitución, ya que como consecuencia de que la protección del medio ambiente es de interés general, se genera el deber del Estado de actuar para asegurar esa protección, así como el derecho de todos los habitantes de la República a vivir en un ambiente sano y equilibrado (Gros Espiell, 1997, 60). Esta parecería ser la interpretación de la Suprema Corte de Justicia, tal como analizaremos en el Capítulo VI del presente estudio.

Nótese que el artículo 47 reconoce expresamente que el acceso al agua y al saneamiento constituyen derechos humanos fundamentales, pero nada se dice sobre el derecho humano a ser protegidos en el goce de un ambiente sano y equilibrado; como si lo hace el artículo $2^{\circ}$ de la Ley $\mathrm{N}^{\circ} 17.283$.

Por otro lado, el derecho a un medio ambiente sano surge del Protocolo Adicional a la Convención Americana sobre Derechos Humanos en materia de Derechos Económicos, Sociales y Culturales (Protocolo de San Salvador) establece en su art. 11 que: "Toda persona tiene derecho a vivir en un medio ambiente sano y a contar con servicios públicos básicos".

Otra de las críticas que se le ha realizado al artículo 47 de la Constitución es que no consagra un deber de proteger el ambiente. Según cierto sector de la doctrina, no sólo debería haberse consagrado un deber de abstención, sino también un deber de protegerlo y preservarlo (Correa Freitas, 1997, p. 41).

Esta es la solución adoptada por la Constitución de la Nación Argentina. La primera parte del artículo 41 establece que: "Todos los habitantes gozan del derecho a un ambiente sano, equilibrado, apto para el desarrollo humano y para que las actividades productivas satisfagan las necesidades presentes sin comprometer las de las generaciones futuras; y tienen el deber de preservarlo. El daño ambiental generará prioritariamente la obligación de recomponer, según lo establezca la ley.” (El subrayado nos pertenece).

Tal como hemos adelantado, esto fue solucionado por el inciso final del artículo 7 de la Ley $\mathrm{N}^{\circ}$ 18.308. En efecto, dicha inciso dispone que: “(...) las personas tienen el deber de proteger el medio ambiente, los recursos naturales y el patrimonio cultural y de conservar y usar cuidadosamente los espacios y bienes, públicos territoriales." (El subrayado nos 
pertenece).

Por último, la doctrina critica que no se incluyó específicamente un deber para el Estado, en lo que refiere a la protección del ambiente (Correa Freitas, 1997, p. 41). Esto también fue solucionado por la Ley $\mathrm{N}^{\circ} 17.283$, al incluir en el artículo $4^{\circ}$ que: "Es deber fundamental del Estado y de las entidades públicas en general, propiciar, un modelo de desarrollo ambientalmente sostenible, protegiendo el ambiente y, si éste fuere deteriorado, recuperarlo o exigir que sea recuperado.”.

IV. La protección del agua en el inciso segundo del artículo 47 de la Constitución de la República

El inciso segundo del artículo 47 de la Constitución fue incluido en la reforma constitucional de 2004, en el 1lamado "plebiscito del agua", impulsado por el Sindicato de Funcionarios de O.S.E., así como por diversas organizaciones sociales (Correa Freitas, 2016, p. 296).

El inciso segundo del artículo 47 de la Constitución establece que: "El agua es un recurso natural esencial para la vida. El acceso al agua potable y el acceso al saneamiento, constituyen derechos humanos fundamentales.". Existe una preocupación del constituyente en el sentido de proteger, preservar, amparar, y asegurar el uso del aprovechamiento del agua, como un bien esencial para el ser humano (Correa Freitas, 2016, p. 297).

El numeral 1 del inciso segundo del artículo 47 de la Constitución establece que: "La política nacional de Aguas y Saneamiento estará basada en:

a) El ordenamiento del territorio, conservación y protección del Medio Ambiente y la restauración de la naturaleza.

b) La gestión sustentable, solidaria con las generaciones futuras, de los recursos hídricos y la preservación del ciclo hidrológico que constituyen asuntos de interés general. Los usuarios y la sociedad civil, participarán en todas las instancias de planificación, gestión y control de recursos hídricos; estableciéndose las cuencas hidrográficas como unidades básicas.

c) El establecimiento de prioridades para el uso del agua por regiones, cuencas o partes de ellas, siendo la primera prioridad el abastecimiento de agua potable a poblaciones. d) El principio por el cual la prestación del servicio de agua potable y saneamiento, deberá hacerse anteponiendo las razones de orden social a las de orden económico. Por último se aclara que: "Toda autorización, concesión o permiso que de cualquier manera vulnere las disposiciones anteriores deberá ser dejada sin efecto.”.

Respecto a este punto, es importante resaltar la Ley $\mathrm{N}^{\circ} 18.610$, de 2 de octubre de 2009 (Ley de Política Nacional de Aguas), establece los principios rectores de la Política Nacional de Aguas dando cumplimiento al inciso segundo del artículo 47 de la Constitución 
de la República.

El numeral 2 del inciso segundo del artículo 47 de la Constitución de la República, en la redacción dada por la reforma constitucional de 2004, establece que: "Las aguas superficiales, así como las subterráneas, con excepción de las pluviales, integradas en el ciclo hidrológico, constituyen un recurso unitario, subordinado al interés general, que forma parte del dominio público estatal, como dominio público hidráulico.”. La Constitución declara el dominio público estatal, por oposición al privado, de todas las aguas, con excepción de las pluviales (Correa Freitas, 2016, p. 297).

El numeral 3 del inciso segundo del artículo 47 de la Constitución establece que: "El servicio público de saneamiento y el servicio público de abastecimiento de agua para el consumo humano serán prestados exclusiva y directamente por personas jurídicas estatales.”. El constituyente utiliza la noción o el concepto de servicio público en sentido estricto o restringido, por cuanto el servicio público es la actividad estatal dirigida a la satisfacción de necesidades colectivas impostergables mediante prestaciones suministradas, directa e indirectamente a los individuos. En este sentido, la doctrina entiende que dicho numeral prohíbe que el servicio público de saneamiento y el servicio público de abastecimiento de agua para el consumo humano, pueda ser prestado por particulares en régimen de concesión de servicio público, como se venía haciendo hasta el año 2004, en los departamentos de Canelones y Maldonado (Correa Freitas, 2016, p. 297).

El numeral 4 del inciso segundo del artículo 47 de la Constitución establece que: "La ley, por tres quintos de votos del total de componentes de cada Cámara, podrá autorizar el suministro de agua, a otro país, cuanto éste se encuentre desabastecido y por motivos de solidaridad.".

Tal como menciona la doctrina, con esta disposición se prohíbe indirectamente la exportación de agua, o la venta al extranjero de agua. Para que pueda suministrarse agua a otro país, se requiere cumplir tres condiciones señaladas por el texto constitucional. Primero, se requiere una ley sancionada por mayoría especial (tres quintos de votos del total de componentes de cada Cámara). Segundo, el país al que se suministra agua debe estar desabastecido. Tercero, los fines de dicho suministro deben ser solidarios, por lo que la doctrina entiende que se excluyen otros fines comerciales, o de contenido económico (Correa Freitas, 2016, p. 298).

V. La protección del ambiente por los artículos 7, 72 y 332 de la Constitución

Tal como hemos adelantado, incluso antes de la reforma constitucional del 1997, la mayoría de la doctrina en nuestro país entendía que el derecho al ambiente se encontraba tutelado implícitamente a través de los artículos 7, 72 y 332 de la Constitución (Pereira Flores, 2000, p. 413; Magariños de Mello, 1997, p. 46; Saettone Montero, 1996, p. 482). 
En primer lugar, porque el derecho a vivir en un ambiente sano y equilibrado es una extensión del derecho a la vida (art. $7^{\circ}$ de la Constitución). Esto por cuando el derecho a la vida supone vivir dignamente, en forma decorosa, y con una adecuada calidad de vida. Por lo que la contaminación de las aguas, del aire, entre otras, afecta el derecho a la vida de todos los habitantes de la República (Correa Freitas, 1997, pp. 36 - 37).

Siguiendo a Magariños de Mello podemos afirmar que el ambiente es la base y el fundamento de la vida (Magariños De Mello, 1997, p. 46). En otras palabras, reconocer el derecho a la vida y negar el derecho a vivir en un ambiente sano y equilibrado implica la negación del primero (Durán Martínez, 1999, p. 81).

Pero además, cierto sector de la doctrina entiende que el derecho a vivir en un ambiente sano y equilibrado se deriva del derecho a la salud, reconocido parcialmente por el artículo 44 de la Constitución de la República (Gros Espiell, 1997, p. 61).

En segundo lugar, porque si bien cuando el artículo 72 se incorporó a la Constitución de 1918, el Derecho Ambiental no existía (Gorosito Zuluaga, 2018, p. 228), dicho artículo, para salvar las posibles omisiones o para permitir una interpretación evolutiva de los derecho fundamentales (Cousillas, 2011, p. 109), previó que: "La enumeración de derechos, deberes y garantías hecha por la Constitución, no excluye los otros que son inherentes a la personalidad humana o se derivan de la forma republicana de gobierno.”.

Cierto sector de la doctrina sostiene que el derecho a gozar de un ambiente sano y equilibrado es inherente a la personalidad humana (Gros Espiell, 1997, p. 60). Es anterior al Estado y la Constitución, siendo un derecho natural de todo ser humano vivir en un ambiente sano y equilibrado (Gorosito Zuluaga, 2018, p. 229). Compartimos esta interpretación. Asimismo, es importante destacar que la doctrina destaca que las convenciones y tratados de contenido ambiental, tienen en virtud del artículo 72 de la Constitución rango constitucional (Gorosito Zuluaga, 2018, p. 232).

Finalmente, el artículo 332 de la Constitución establece que: "Los preceptos de la presente Constitución que reconocen derechos a los individuos, así como los que atribuyen facultades e imponen deberes a las autoridades públicas, no dejarán de aplicarse por falta de la reglamentación respectiva, sino que ésta será suplida, recurriendo a los fundamentos de leyes análogas, a los principios generales de derecho y a las doctrinas generalmente admitidas.".

VI. La sentencia de la SCJ que declara constitucional el Sistema Nacional de Áreas Naturales Protegidas en virtud del artículo 47 de la Constitución

La sentencia que analizaremos en el presente apartado es la $\mathrm{N}^{\circ} 1588$, de 26 de noviembre de 2018. La misma refiere a la acción de inconstitucionalidad de la Ley $\mathrm{N}^{\circ} 17.234$, de 22 de febrero de 2000, modificada por la Ley $\mathrm{N}^{\circ} 17.930$, de 19 de diciembre de 2005. Nos 
tocó asesorar a la Dirección Nacional de Medio Ambiente, al contestar la acción de inconstitucionalidad, y creemos que es un gran leading case en nuestro Derecho Ambiental. No sólo porque el Estado refuerza la gestión del Sistema Nacional de Áreas Naturales Protegidas, pero además, por los propios argumentos desarrollados por la propia Suprema Corte de Justicia.

La Ley $\mathrm{N}^{\circ}$ 17.234, declaró de interés general la creación y gestión de un Sistema Nacional de Áreas Naturales Protegidas, como instrumento de aplicación de las políticas y planes nacionales de protección ambiental. Por su parte, el literal "g" del artículo 7 de la Ley $N^{\circ} 17.283$ calificó al Sistema Nacional de Áreas Naturales Protegidas, como uno de los instrumentos de gestión ambiental previstos por nuestro Derecho.

El artículo 5 de la Ley $\mathrm{N}^{\circ} 17.234$ en su redacción original, dispuso que la incorporación de áreas al Sistema Nacional de Áreas Naturales Protegidas, se realizaría por el Poder Ejecutivo, a propuesta del Ministerio de Vivienda, Ordenamiento Territorial y Medio Ambiente, incluyendo las áreas pertenecientes al Estado, y de los "particulares que a tales efectos prestaren su consentimiento". Es decir que, para que un padrón de propiedad privada integrara un área del SNAP, el propietario debería previamente prestar su consentimiento.

Por su parte, la redacción original del artículo 8 del Decreto $\mathrm{N}^{\circ} 52 / 005$, de 16 de febrero de 2005 (Reglamentario de la Ley $N^{\circ}$ 17.234), estableció el procedimiento a seguir para obtener dicho consentimiento: "La propuesta se realizará bajo la forma de un contrato, en el que se detallarán en forma precisa las condiciones de uso y manejo a que quedará sujeta el área en cuestión, de acuerdo a la categoría de manejo seleccionada, de conformidad con lo dispuesto en la Ley y el presente decreto. A partir de la notificación personal o por edictos, los propietarios tendrán un plazo máximo de 90 (noventa) días para manifestar su consentimiento. Vencido este plazo sin que el propietario haya manifestado su consentimiento en forma expresa, quedará expedita la vía para la aplicación de lo dispuesto en el artículo $6^{\circ}$ de la Ley $\mathrm{N}^{\mathrm{o}} 17.234$ (...).”.

Es decir que de conformidad con dicho artículo, si el propietario no prestaba su consentimiento para que su padrón forme parte de un área del SNAP, el Estado quedaba habilitado para seguir la vía prevista por el artículo 6 de la Ley $\mathrm{N}^{\circ} 17.234$, el cual declaraba de utilidad pública la expropiación de aquellas áreas, cuyos titulares no prestaren su consentimiento para la incorporación de los mismos al Sistema Nacional de Áreas Naturales Protegidas.

La Ley $\mathrm{N}^{\circ} 17.930$, de 19 de diciembre de 2005 (arts. 362 y 363), modificó los artículos 5 y 6 de la Ley $\mathrm{N}^{\circ} 17.234$, eliminando la referencia al consentimiento de los particulares que quedó derogada. Posteriormente, el procedimiento previsto para recabar dicho consentimiento - ya derogado - se eliminó del artículo $8^{\circ}$ del Decreto $\mathrm{N}^{\circ} 52 / 005$, a través del Decreto $\mathrm{N}^{\circ} 294 / 019$, de 30 de setiembre de 2019 (art. $1^{\circ}$ ). 
Esta modificación permitió la incorporación de diversas áreas al Sistema Nacional de Áreas Naturales Protegidas. A saber:

1. Quebrada de los Cuervos y Sierras del Yerbal (Decreto No 462/008, de 29 de setiembre de 2008; Decreto $N^{\circ}$ 524/008, de 27 de octubre de 2008; y Decreto $\mathrm{N}^{\circ}$ 60/020, de 14 de febrero de 2020).

2. Esteros de Farrapos e Islas del Río Uruguay (Decreto $N^{\circ}$ 579/008, de 27 de noviembre de 2008; Decreto $N^{0} 343 / 015$, de 16 de diciembre de 2015).

3. Cabo Polonio (Decreto No 337/009, de 20 de julio de 2009).

4. Valle del Lunarejo (Decreto $N^{0} 476 / 009$, de 14 de octubre de 2009).

5. Localidad Rupestre de Chamangá (Decreto N N 11/010, de 12 de enero de 2010; Decreto $N^{\circ}$ 129/010, de 20 de abril de 2010; Decreto No 6/011, de 19 de enero de 2011). 6. San Miguel (Decreto $N^{\circ}$ 54/010, de 8 de febrero de 2010; Decreto $N^{\circ} 333 / 019$, de 4 de noviembre de 2019).

7. Laguna de Rocha (Decreto $N^{0}$ 61/010, de 18 de febrero de 2010).

8. Cerro Verde (Decreto No 285/011, de 10 de agosto de 2011).

9. Rincón de Franquía (Decreto No 121/013, de 17 de abril de 2013).

10. Grutas del Palacio (Decreto $N^{\circ} 153 / 013$, de 21 de mayo de 2013).

11. Laguna Garzón (Decreto $\mathrm{N}^{\circ} 341 / 014$, de 21 de noviembre de 2014; Decreto $\mathrm{N}^{\mathrm{o}}$ 388/014, de 29 de diciembre de 2014).

12. Montes del Queguay (Decreto No 343/014, de 25 de noviembre de 2014).

13. Humedales de Santa Lucía (Decreto No 55/015, de 9 de febrero de 2015).

14. Esteros y Algarrobales del Rio Uruguay (Decreto No 341/015, de 16 de diciembre de 2015).

15. Isla de Flores (Decreto $\mathrm{N}^{\circ} 43 / 018$, de 23 de febrero de 2018).

16. Paso Centurión y Sierra de Ríos (Decreto $N^{\circ}$ 198/019, de 8 de julio de 2019).

17. Laguna de Castillos (Decreto $N^{\circ} 59 / 020$, de 14 de febrero de 2020).

Anteriormente, la necesidad de contar con el consentimiento de los particulares, inviabilizó la incorporación de áreas al Sistema Nacional de Áreas Naturales Protegida. Nótese que las primeras áreas protegidas incorporadas al Sistema Nacional de Áreas Naturales Protegidas datan del año 2008; casi 10 años posteriores a la promulgación de la Ley $\mathrm{N}^{\circ}$ 17.234.

Como habíamos adelantado, la acción de inconstitucionalidad objeto de la sentencia que estamos analizando, se realizó contra la Ley $\mathrm{N}^{\circ} 17.234$, y su modificativa, la Ley $\mathrm{N}^{\circ}$ 17.930. Los propietarios de un campo ubicado en el área natural protegida "Humedales de Santa Lucía”, incorporada al Sistema Nacional de Áreas Naturales Protegidas, por Decreto $\mathrm{N}^{\mathrm{o}} 55 / 015$, de 9 de febrero de 2015, solicitan que se declare la inconstitucionalidad de la Ley $\mathrm{N}^{\circ} 17.234$, en la redacción dada por la Ley $\mathrm{N}^{\circ} 17.930$, por ser violatorias de los artículos 7 y 32 de la Constitución Nacional. 
Asimismo se señaló que: “Además de resultar una limitación violatoria del derecho de propiedad consagrada constitucionalmente, se agravó la misma al eliminar la etapa previa de estudio, coordinación y eventual consentimiento de los propietarios a la eventual inclusión.”. En la misma línea, argumentan que la modificación de la Ley № 17.930 eliminó un procedimiento con determinadas garantías para los propietarios: consentimiento (art. 5 de la Ley $\mathrm{N}^{\circ} 17.234$ ), notificación personal, y eventual celebración de un contrato (art. 8 del Decreto $\mathrm{N}^{\circ}$ 52/005).

La Suprema Corte de Justicia entendió que existió poca claridad en la individualización requerida por el artículo 512 del Código General del Proceso (Ley $N^{\circ} 15.982$, de 18 de octubre de 1988): "En efecto (...) la única impugnación que puede ser individualizada y que no resultaría alcanzada por la inadmisibilidad referida en el Considerando anterior es la referida al artículo 6 de la Ley No. 17.234.”. Respecto a este punto, se entendió que la disposición en cuestión (artículo 6 de la Ley $\mathrm{N}^{\circ}$ 17.234) resulta absolutamente ajustada a lo dispuesto por el artículo 47 de la Constitución, en cuanto dispone que la protección del ambiente es de interés general.

La Corte aclaró además que: “(...) el art. 362 de la Ley No. 17.930 que dio nueva redacción al art. 5 de la Ley No. 17.234 simplemente regula la incorporación al sistema de áreas naturales protegidas por parte del Poder Ejecutivo a propuesta del MVOTMA (...)”. En este sentido, se argumentó que: “(...) el art. 5 en la redacción vigente no regula supuesto alguno de expropiación, esto es, de traslación dominial forzosa de un bien a manos del Estado, sino que regula cómo los bienes públicos o privados se incorporan al sistema de áreas naturales protegidas.".

En lo que refiere a las medidas de protección previstas por el artículo 8 de la Ley $\mathrm{N}^{\circ}$ 17.234 (limitaciones o prohibiciones), la Corte concluyó que: "Dicha incorporación, puede aparejar determinadas medidas de protección de aquellas áreas consideradas protegidas, pero estas limitantes al derecho de propiedad son una herramienta necesaria e idónea para tutelar el derecho a un medio ambiente sano y sustentable" (art. 47 de la Carta). En este sentido, se desprende que la Corte de alguna forma entiende que el derecho a un ambiente sano y equilibrado se desprende del artículo 47 de la Constitución.

En lo que respecta a la propiedad y el ambiente, la Corte resalta que: "El legislador, en el balance de derechos fundamentales, pretendió dar preferencia al derecho al medio ambiente (...)”. Pero además, se argumentó que: “(...) el derecho a la propiedad no es un derecho subjetivo perfecto que no admita limitaciones por razones de interés general, por el contrario, puede ser restringido en su protección si existe razonable motivo en aras del bien común.”. En el caso en cuestión, dicha fundamentación estaría dada por el artículo $1^{\circ}$ de la Ley $N^{\circ} 17.234$, que declara de interés general la creación y gestión de un Sistema Nacional de Áreas Naturales Protegidas.

Y se concluye que: "En el caso, no se licua el disfrute en el ejercicio de un derecho consti- 
tucional, como es el derecho de propiedad, desnaturalizándolo mediante el establecimiento de una serie de gravámenes que tornan estéril el ejercicio de tal derecho. Y que: "Los actores, incorrectamente, asimilan limitación del derecho de propiedad (restricciones al ejercicio) con la privación que es la medida de intervención más intensa, porque lo que produce es el traspaso dominial de un bien del particular al Estado.".

Por último, en lo que respecta a la inconstitucionalidad del artículo 6 de la Ley $\mathrm{N}^{\circ} 17.234$, en la redacción dada por el artículo 363 de la Ley $\mathrm{N}^{\circ}$ 17.930, se argumentó que: "El hecho de que el art. 6 de la Ley 17.234 en su redacción original declara de utilidad pública la expropiación de aquellos bienes cuyos titulares no habían prestado su consentimiento para la incorporación al Sistema Nacional de Áreas Protegidas y que, por obra del art. 353 de la Ley No. 17.930 se haya eliminado la referencia al consentimiento no viola, en modo alguno, el derecho de propiedad.".

\section{Conclusiones}

La protección del ambiente aparece consagrada en el artículo 47 de la Constitución de la República, el cual se ubica dentro del Capítulo II, dentro de la Sección II (Derechos, Deberes y Garantías). Asimismo, dicha protección se desprende de los artículos 7, 72 y 332 de la Constitución de la República.

La protección constitucional del ambiente es un gran mojón en el desarrollo del Derecho Ambiental, aunque el texto constitucional presenta diversas críticas que han sido señaladas en el presente estudio. La mayor crítica que se le puede hacer al artículo 47 de la Constitución de la República es que no se consagra expresamente un derecho a los habitantes (de las generaciones presentes y futuras) al goce y disfrute de un ambiente sano y equilibrado.

El artículo 47 de la Constitución dio paso al desarrollo del Derecho Ambiental en nuestro país, permitiendo la limitación de ciertos derechos, tales como la propiedad. Un claro ejemplo es la creación del Sistema Nacional de Áreas Naturales Protegidas, a partir de la Ley $\mathrm{N}^{\circ} 17.234$, de 22 de febrero de 2000, ya que de conformidad con el artículo $8^{\circ}$ de dicha ley, el Poder Ejecutivo, a propuesta del Ministerio de Vivienda, Ordenamiento Territorial y Medio Ambiente, puede establecer ciertas limitaciones o prohibiciones respecto a las actividades que se realicen en las áreas comprendidas en el SNAP y zonas adyacentes. Una de las pocas sentencias ambientales que han llegado a la Suprema Corte de Justicia discutió justamente la disposición constitucional y la constitucionalidad del Sistema Nacional de Áreas Naturales Protegidas. La misma no sólo reconoce la constitucionalidad de la Ley $\mathrm{N}^{\circ} 17.234$, modificada por la Ley $\mathrm{N}^{\circ} 17.930$, sino que además reconoce que el derecho a vivir en un ambiente sano y equilibrado se desprende del artículo 47 de la Constitución de la República. 


\section{BIBLIOGRAFÍA CONSULTADA}

BIASCO, Emilio (1999). Derecho Ambiental General. Fundación de Cultura Universitaria.

BLENGIO VALDÉS, Mariana (2003). Derecho humano a un ambiente sano. Revista de Derecho, año 2, no. 4, 5-17.

BLENGIO VALDÉS, Mariana. Manual de Derechos Humanos. https://publicaciones. fder.edu.uy/index.php/me/article/view/203/194

CORREA FREITAS, Ruben \& VÁZQUEZ, Cristina (1997). La reforma constitucional de 1997. Fundación de Cultura Universitaria.

CORREA FREITAS, Ruben (2016). Derecho Constitucional Contemporáneo. Fundación de Cultura Universitaria.

GROS ESPIELL, Héctor (1997). La protección del medio ambiente en el Derecho Constitucional. Durán Martínez, Reforma Constitucional 1997 (pp. 53 - 65).

COUSILLAS, Marcelo (2011). La protección del ambiente en la Constitución. En M. BLENGIO. J.A. CAGNONI, Estudios constitucionales. En honor a Héctor Gros Espiell (pp. 105 - 120). La Ley Uruguay.

GOROSITO ZULUAGA, Ricardo (2018). El artículo 72 de la Constitución uruguaya como norma pórtico, puente o de coordinación entre el Derecho ambiental internacional o global y el Derecho ambiental en Uruguay". Revista de Legislación Uruguaya. Sistematizada y analizada. (Año IX, $\mathrm{N}^{\circ} 1$ ), $227-235$.

GOROSITA ZULUAGA, Ricardo (2019). ESTUDIOS DE DERECHO AMBIENTAL. PARTE GENERAL. Objeto protegido. Principios. Protección constitucional. La Ley Uruguay.

IGLESIAS ROSSINI, Gonzalo Fernando (2016). El derecho a gozar de un ambiente sano: Relaciones entre la salud y el Ambiente. Revista de la Facultad de Derecho. (40), 159-176.

MAGARIÑOS DE MELLO, Mateo (1997). La protección del medio ambiente. En. A. Durán Martínez, Reforma Constitucional 1997 (pp. 43 - 51).

PEREIRA FLORES, María Victoria (2000). El derecho al ambiente como derecho fundamental, desde la perspectiva del derecho positivo uruguayo. En A. Durán Martínez, Estudios en memoria de Héctor Frugone Schiavone (pp. 413 - 419). AMALIO M. FERNÁNDEZ.

ROTONDO, Felipe (2015). Derechos fundamentales y Derecho Administrativo. Revista de Derecho Público (Año 24; N 47), 87 - 102.

SAETTONE MONTERO, Mariella (1996). Marco normativo de la protección del medio ambiente en nuestro derecho positivo. En. Estudios Jurídicos en Memoria de Alberto Ramon Real (479 - 491). 
SAETTONE MONTERO, Mariella (2003). La protección del medio ambiente por la Ley $\mathrm{N}^{\circ} 17.234$ (áreas protegidas) y la Ley $\mathrm{N}^{\circ} 17.283$ que declara de interés general de acuerdo con el art. 47 de la Constitución la protección del medio ambiente. Revista de Derecho Público. (24), 117 - 126.

Fecha de recepción: 31 de mayo 2020.

Fecha de aceptación: 20 de junio 2020. 